\title{
Adaptações curriculares para estudantes com deficiência intelectual: desafios e perspectivas
}

Curricular adaptations for students with intellectual disabilities: challenges
and perspectives

Adaptaciones curriculares para estudiantes con discapacidad intelectual: retos y perspectivas

\section{Vania Salete Cassol Daga}

Mestra pela Universidade Comunitária da Região de Chapecó, Chapecó, Santa Catarina, Brasil. vaniasale@yahoo.com.br

ORCID - https://orcid.org/0000-0002-8862-4066

\section{Leonel Piovezana}

Professor doutor na Universidade Comunitária da Região de Chapecó, Chapecó, Santa Catarina, Brasil. leonel@unochapeco.edu.br

ORCID - https://orcid.org/0000-0001-8577-319X

\section{Tania Mara Zancanaro Pieczkowski}

Professora doutora na Universidade Comunitária da Região de Chapecó, Chapecó, Santa Catarina, Brasil. taniazp@unochapeco.edu.br

ORCID - https://orcid.org/0000-0002-5257-7747

Recebido em 26 de setembro de 2020

Aprovado em 30 de novembro de 2020

Publicado em 21 de dezembro de 2020

\section{RESUMO}

As práticas educativas de adaptações curriculares para estudantes que possuem deficiência intelectual são o tema tratado no presente artigo, resultado de uma pesquisa do mestrado em educação, que buscou responder à seguinte questão: como os professores compreendem e fazem uso das adaptações curriculares no processo de inclusão dos estudantes com deficiência intelectual no Ensino Médio? O objetivo deste estudo foi analisar como os professores de estudantes com deficiência intelectual, incluídos no Ensino Médio, compreendem e fazem uso das adaptações curriculares atendendo à política de Educação Especial. Trata-se de uma pesquisa qualitativa, com delineamento de casos, que envolveu o estudo com docentes atuantes no Ensino Médio da rede estadual do município de Chapecó (SC). A coleta de dados foi por entrevistas semiestruturadas, com análise do conteúdo em Bardin (2016). A fundamentação teórica amparada em Vigotsky ${ }^{1}$ possibilitou identificar que, mesmo diante das dificuldades estruturais enfrentadas na atuação inclusiva, os professores conseguem promover adaptações curriculares de pequeno porte para estudantes com deficiência intelectual. O êxito da educação inclusiva está associado à formação acadêmica e continuada e ao compromisso profissional.

Palavras-chave: Adaptações curriculares; Deficiência intelectual; Ensino Médio. 
http://dx.doi.org/10.5902/1984686X55382

\section{ABSTRACT}

The educational practices of curricular adaptations for intellectually disabled students are the theme addressed in this paper which is the result of a master in education thesis and sought answering the following: How do teachers understand and use curricular adaptations to include intellectually disabled students in high school? The aim was to analyze how these teachers from high school students with intellectual disabilities understand and make use of curricular adaptations in compliance with Special Education policy. This is a qualitative research with case outlines, which involved the study with high school teachers in the state system of the municipality of Chapecó, SC. Data collection was carried out through semistructured interviews, with content analysis supported by Bardin (2016). The theoretical basis supported by Vigotsky allowed us to identify that, despite the structural difficulties faced in the performance of inclusive education, teachers were able to promote small curricular adaptations for intellectually disabled students. This achievement is associated with academic and continuing education, and professional commitment as well.

Keywords: Curricular adaptation; Intellectual disability; High School.

\section{RESUMEN}

Las prácticas educativas de adaptaciones curriculares para estudiantes con discapacidad intelectual son el tema que se aborda en este artículo, resultado de una investigación de la maestría en educación, que buscó dar respuesta a la siguiente pregunta: ¿Cómo los docentes entienden y hacen uso de las adaptaciones curriculares en el proceso de inclusión de estudiantes con discapacidad intelectual en la secundaria? El objetivo de este estudio fue analizar cómo los profesores de los estudiantes con discapacidad intelectual, incluidos en la escuela secundaria, comprenden y hacen uso de las adaptaciones curriculares de acuerdo con la política de Educación Especial. Se trata de una investigación cualitativa, con bosquejo de casos, que involucró el estudio con docentes que laboran en la secundaria de la red estatal en el municipio de Chapecó (SC). La recogida de datos se llevó a cabo por medio de entrevistas semiestructuradas, con análisis de contenido en Bardin (2016). El fundamento teórico apoyado en Vigotsky permitió identificar que, a pesar de las dificultades estructurales enfrentadas en el desempeño de la educación inclusiva, los docentes logran promover pequeñas adaptaciones curriculares para estudiantes con discapacidad intelectual. El éxito de la educación inclusiva está asociado con la educación académica y continua y el compromiso profesional.

Palabras clave: Adaptaciones curriculares; Discapacidad intelectual; Escuela secundaria. 


\section{Introdução}

Compreendemos a complexidade que é realizar a docência com práticas que promovam a educação para todos e que atendam às novas perspectivas de uma educação que transcenda os muros da escola. Isso requer uma série de questões que obrigatoriamente nos desafiam enquanto professores e, que ao mesmo tempo, nos afastam das práticas tradicionais, pois:

Quanto mais conhecemos determinado fato ou assunto, mais nos sentimos seguros diante dele. $O$ novo gera insegurança e instabilidade, exigindo reorganização, mudança. É comum sermos resistentes ao que nos desestabiliza. Sem dúvida, as ideias inclusivas causaram muita desestabilidade e resistência (MINETTO, 2008, p. 17).

Diante destas questões, percebemos que para a inclusão escolar acontecer são necessárias algumas mudanças no contexto das escolas, através de reflexões comprometidas e responsáveis, com políticas públicas de inclusão efetivas. As adaptações curriculares são ferramentas que vêm complementar as ações na efetivação de uma educação que atenda a todos, com respeito às diferenças e às múltiplas formas de educar.

A escola no Brasil passou por transformações através de seu processo de democratização. Parte das pessoas com deficiência, que no passado estavam excluídas, agora se encontram matriculadas e frequentando as escolas. Isso, porém, não significa que estão incluídas e com condições de avançarem nos seus processos de aprendizagem. É valoroso se ter uma nova concepção sobre a escola contemporânea. Como afirma Larrosa (2017), estamos assistindo à dissolução da escola tradicional:

A escola, diz-se, já não é o único lugar da educação, e talvez não seja o mais adequado. A escola, diz-se, se transformou em um lugar anacrônico, obsoleto, desagradável e ineficaz. A aprendizagem, diz-se, ultrapassa as fronteiras da escola e se dá em todos os lugares e a qualquer momento. A crítica da escola se tornou um lugar-comum, e a educação ficou sem um lugar próprio. [...]. E é agora, neste momento de crítica e dissolução da forma da escola, que queremos repensá-la amorosamente para reencontrar sua especificidade e sua autêntica natureza (LARROSA, 2017, p. 1).

É com esse discernimento de Larrosa (2017) que comungamos nossos princípios frente à escola, sobretudo, com as escolas inclusivas para os estudantes com necessidades especiais - deficiência intelectual. Essas devem promover uma inclusão respeitosa sem naturalizá-los, mas entendê-los a partir da realidade que os contempla, por meio dos contributos escolares. Nessa perspectiva, contamos com a ação dos professores que são os condutores e responsáveis pela imersão dos estudantes da Educação Especial na 
escola inclusiva. No entanto, essas concepções precisam estar de acordo com o que prevê a política da inclusão escolar.

O Brasil conquistou relevante avanço no processo de educação inclusiva a partir da Lei de Diretrizes e Bases da Educação Nacional (LDBEN) n. 9.394/1996, em conformidade com a Constituição Federal de 1988, que garante a todos os mesmos direitos. A partir dessas legislações, a escolarização das pessoas com deficiência ganha um novo capítulo na história educacional brasileira. Isso porque "[...] a luta pela inclusão das pessoas com deficiência é fortalecida no todo, deixando para trás a história de séculos de descaso e discriminação em relação às suas necessidades diferenciadas." (PIRES; SANCHES; TORRES, 2011, p. 2).

Com todos os ganhos pautados na legislação, o processo de inclusão dos estudantes com necessidades especiais no ensino regular ainda precisa ser revisto, a fim de atender às situações particulares de cada estudante. Para que isso seja possível, é necessário construir o Projeto Político-Pedagógico (PPP) com o envolvimento de todos os segmentos ligados às instituições de ensino. Ele deve contemplar as diferenças nas escolas por meio de um currículo que possa dar conta das diferentes situações do contexto, tendo como bandeira maior o desenvolvimento e a socialização de todos os estudantes, pois é por intermédio de:

\footnotetext{
Um currículo centrado fundamentalmente nos conteúdos conceituais e nos aspectos mais acadêmicos, que propõe sistemas de avaliação baseados na superação de um nível normativo igual a todos, lança ao fracasso alunos com mais dificuldades para avançar nestes âmbitos. Os currículos mais equilibrados, nos quais o desenvolvimento social e pessoal também tem importância e em que a avaliação seja feita em função do progresso de cada aluno, facilitam a integração dos alunos (MARCHESI, 2004, p. 39).
}

Essas são as razões que nos mobilizaram para a busca de mais subsídios sobre como os professores do Ensino Médio podem contribuir com os estudantes que possuem deficiência intelectual, de forma que possam concluir a Educação Básica. Salientamos que as pessoas com essa deficiência possuem especificidades que nem sempre são facilmente perceptíveis como na deficiência física, auditiva, visual ou outras. Isso requer do professor maiores domínios de conhecimentos específicos de como ocorre o desenvolvimento cognitivo para esses estudantes.

Segundo Paulon, Freitas e Pinho (2005), a deficiência intelectual ${ }^{2}$, termo conhecido em outros tempos por deficiência mental ${ }^{3}$, caracteriza-se por um funcionamento intelectual abaixo da média em conjunto com limitações em vários aspectos. 
Nossas reflexões como pesquisadores circundam sobre os estudantes com deficiência intelectual que estão frequentando o Ensino Médio na rede pública do estado de Santa Catarina (SC). Os dados do Censo Escolar de 2018, destacados na Tabela 1, mostram que houve uma redução na matrícula dos estudantes com deficiência intelectual do Ensino Fundamental para o Ensino Médio em todas as redes de ensino. Essas constatações também se manifestam na 4ª CRE (Coordenadoria Regional de Educação) de Chapecó (SC).

Tabela 1 - Matrículas: deficiência intelectual da Educação Básica 2018 - Regional de Chapecó

\begin{tabular}{c|c|l|l|l}
\hline \multirow{2}{*}{ Ano } & \multicolumn{4}{|c}{ Ensino Fundamental Anos Iniciais - EF Al } \\
\cline { 2 - 5 } & $\begin{array}{l}\text { Deficiência } \\
\text { Intelectual }\end{array}$ & $\begin{array}{l}\text { Outras } \\
\text { deficiências }\end{array}$ & $\begin{array}{l}\text { Total de matrículas na } \\
\text { Educação Especial - EF } \\
\text { Al }\end{array}$ & $\begin{array}{l}\text { Total de matrículas } \\
\text { no EF Al }\end{array}$ \\
\hline 2018 & 194 & 155 & 349 & 16.844 \\
\hline
\end{tabular}

\begin{tabular}{c|c|l|l|l}
\hline \multirow{2}{*}{ Ano } & \multicolumn{4}{|c}{ Ensino Fundamental Anos Finais - EF AF } \\
\cline { 2 - 5 } & $\begin{array}{l}\text { Deficiência } \\
\text { Intelectual }\end{array}$ & $\begin{array}{l}\text { Outras } \\
\text { deficiências }\end{array}$ & $\begin{array}{l}\text { Total de matrículas na } \\
\text { Educação Especial - } \\
\text { EF AF }\end{array}$ & $\begin{array}{l}\text { Total de matrículas } \\
\text { no EF AF }\end{array}$ \\
\hline 2018 & 225 & 160 & 385 & 13.710 \\
\hline
\end{tabular}

\begin{tabular}{c|c|c|c|c}
\hline \multirow{2}{*}{ Ano } & \multicolumn{4}{|c}{ Ensino Médio* } \\
\cline { 2 - 5 } & $\begin{array}{l}\text { Deficiência } \\
\text { Intelectual }\end{array}$ & $\begin{array}{l}\text { Outras } \\
\text { deficiências }\end{array}$ & $\begin{array}{l}\text { Total de matrículas na } \\
\text { Educação Especial }\end{array}$ & $\begin{array}{l}\text { Total de matrículas } \\
\text { no Ensino Médio }\end{array}$ \\
\hline 2018 & 105 & 85 & 190 & 8.814 \\
\hline
\end{tabular}

Fonte: INEP (2018).

Frente aos dados apresentados justificamos a relevância da pesquisa no Ensino Médio voltada para os estudantes com deficiência intelectual. Essa área de ensino carece de mais estudos científicos que mostrem a possibilidade de acesso ao conhecimento das pessoas com deficiência intelectual.

Em relação a esta causa que a intenção macro da pesquisa ocorreu. Foi perguntado aos professores que atuam diretamente com estudantes com deficiência intelectual no Ensino Médio regular: como compreendem e fazem uso das adaptações curriculares no processo de inclusão dos estudantes com deficiência intelectual? Entendendo serem práticas educativas integradoras, ratificamos a teoria histórico-cultural de Vigotsky (1997), 
que entende a construção do sujeito nos contextos, pelas relações e interações que estabelecem com as diversidades.

A educação tem um papel significativo na humanização dos indivíduos e na transformação da sociedade. Para Gadotti (2003), ela necessita de suportes teóricos que apontem para as possibilidades, uma vez que a teoria educacional visa à formação do homem integral, ao desenvolvimento de sua potencialidade e, assim, propiciar que se torne sujeito de sua própria história, e não objeto dela.

As adaptações curriculares no processo de inclusão escolar são instrumentos de discussões apresentadas neste artigo. Compreendemos que a realização é o caminho para 0 atendimento das necessidades específicas de aprendizagem dos estudantes que possuem necessidades educacionais e que estão incluídos no ensino regular.

Esta investigação ocorreu a partir das seguintes questões: Qual a compreensão docente acerca das adaptações curriculares para os estudantes com deficiência intelectual? Os professores adotam currículos adaptados para os estudantes com deficiência intelectual incluídos no Ensino Médio e como acontece o processo de adaptação curricular? Que materiais são adaptados para os estudantes com deficiência intelectual do Ensino Médio regular? Como os estudantes com deficiência intelectual se beneficiam de adaptações curriculares? Quais os desafios docentes para realizar adaptações no currículo para estudantes com deficiência intelectual no Ensino Médio regular?

A pesquisa nos possibilitou debater e refletir concepções tradicionais em relação às pessoas com deficiência intelectual revelada por diagnósticos clínicos, estigmatizadas, tornando, assim, difícil a superação dos pré-conceitos atribuídos socialmente. Temos ciência de que estes estudantes detêm limitações na aquisição de habilidades acadêmicas, mas a escola pode, por meio de suas práticas, promover mudanças em relação à forma como interpreta e conduz suas ações pedagógicas.

\section{Metodologia do trabalho}

O processo de investigação sobre a temática ocorreu por meio de uma pesquisa qualitativa em duas escolas da rede pública estadual de Chapecó (SC). A obtenção das materialidades empíricas da pesquisa aconteceu mediante entrevistas semiestruturadas, com oito professores de estudantes com deficiência intelectual, incluídos no Ensino Médio regular. 
A definição das escolas, locus da pesquisa, deu-se pela Diretoria da Educação Especial da 4" Coordenadoria Regional de Educação (CRE) de Chapecó. Os critérios estabelecidos para a escolha foram: a escola ter de três a cinco estudantes com deficiência intelectual, matriculados e frequentando o ensino regular e que, pelo menos em uma das escolas, tivesse a modalidade do Ensino Médio Inovador (EMI), para comparar uma escola com regime integral de outra com ensino comum.

Os critérios estabelecidos para definir os sujeitos participantes da pesquisa foram: ser professor (ou segundo professor) de turma; estar atuando diretamente com os estudantes com deficiência intelectual no Ensino Médio; e ter no mínimo seis meses de tempo de serviço na escola.

A investigação ${ }^{4}$ realizada com os professores, nas escolas, foi por meio de entrevistas semiestruturadas e do diálogo com os docentes colaboradores. Buscamos observar se os professores entrevistados adotavam práticas pedagógicas de adaptação do currículo como alternativas de descomplexificar o acesso ao conhecimento dos estudantes com deficiência intelectual.

Concluídas as entrevistas, as mesmas foram transcritas integralmente e o processo de análise de conteúdo seguiu rigorosamente as três fases, referenciadas em Bardin (2016), que são: pré-análise; exploração do material; e tratamento dos resultados, inferência e interpretação.

A pesquisa seguiu todas as normas que estabelece os princípios éticos quanto ao bem-estar, à proteção e aos direitos dos participantes. Foi submetida e aprovada pelo Comitê de Ética em Pesquisa pelo (CAEE) ํo. 18723619.1.000.0116 da UNOCHAPECÓ.

\section{Adaptações curriculares para estudantes com deficiência intelectual}

As categorias centrais do estudo se definiram considerando as repercussões docentes que se reproduziram nas entrevistas de maneira latente, ficando definidas em: deficiência intelectual e as adaptações curriculares na compreensão docente da Educação Especial; o emprego das adaptações curriculares para estudantes com deficiência intelectual incluídos no Ensino Médio regular; e desafios docentes acerca da realização das adaptações curriculares.

No diálogo estabelecido com os docentes, foram observados e comparados os contextos escolares em relação à frequência dos estudantes com deficiência intelectual e as concepções sobre as práticas de adaptações curriculares para a escolarização no 
Ensino Médio regular. Escutas que se balizaram nas interpretações que possuíam e possuem em relação à escolarização inclusiva e no atendimento pedagógico diferenciado com o emprego de adaptações no currículo e no processo ensino-aprendizagem.

De acordo com a Política Nacional da Educação Especial na Perspectiva da Educação Inclusiva (BRASIL, 2008), a partir da democratização da escola, existe um antagonismo demarcado pela inclusão/exclusão. Enquanto os sistemas universalizam os acessos, de certa forma, continuam excluindo os indivíduos considerados fora dos padrões homogeneizadores da escola.

Assim, o estudante com deficiência intelectual é considerado um desafio para os docentes na escola, habituados a trabalhar com alunos considerados ideais ou de um modelo único de aprendizagem, sem considerar a diversidade humana e as possibilidades de escolarização de pessoas com deficiência intelectual (PADILHA, 2001).

A seguir, apresentamos a análise das materialidades geradas pela pesquisa com os docentes colaboradores. Foram eleitas em três categorias centrais e, a partir delas, ocorreu a interpretação com base na análise de conteúdo em Bardin (2016).

\section{Deficiência intelectual e adaptações curriculares na compreensão docente da Educação Especial}

A caracterização dos estudantes com deficiência intelectual esteve, ao longo da história, demarcada pelas limitações que os mesmos possuem em função da deficiência. Mesmo com os avanços científicos e legislações a favor, o que se percebe é que esses sofrem preconceitos com visões equivocadas. Situações ainda piores quando considerados incapazes, sem condições de aprender, reconhecidos pelas dificuldades na leitura, na escrita, no cálculo, situações que persistem na cultura escolar docente.

Eles não estão alfabetizados, não conseguem compreender o que falamos, não aprendem a escrever, a ler corretamente, têm muitas dificuldades. A maioria deles não consegue ler. Apenas faz associações das palavras ou da letra inicial, por exemplo: A de avião, C de casa (Docente 4).

De acordo com o relato dos docentes da pesquisa, as características que identificam os estudantes do Ensino Médio com deficiência intelectual estão ligadas diretamente às condições cognitivas, como pessoas que não aprendem, que não são alfabetizados. Ficou evidente que os professores concebem a escolarização dos estudantes com deficiência intelectual da mesma maneira como lidam com as diferenças na escola inclusiva. Muitos 
professores ainda estão amparados em práticas tradicionais, no sentido que alfabetizar é escrever, ler, calcular, desconsiderando como aprendizagem outros planos negligenciados que ficam sufocados, como o afetivo, dentre outros.

Na maioria dos casos, os estudantes com deficiência intelectual são trabalhadores, que chegam ao Ensino Médio devido à persistência e a um querer que impressiona. Pelas duras lutas, eles sofrem e se adequam à organização das escolas, que nem sempre se condicionam ao atendimento específico e diferenciado. São apercebidos por condicionantes históricos que os legitimaram biologicamente, devido à ideia de imutabilidade da deficiência; são analisados pela individualidade e, por essa concepção, as diferenças e fragilidades tomam formas gigantescas, que acabam por encobrir as possibilidades de desenvolvimento. Nessa acepção, referenciamos Vigotsky (1997), quando relata que essa é uma construção que carece de certas desconstruções.

Outras compreensões da escolarização de pessoas com deficiência intelectual na escola inclusiva passam por olhares adversos de alguns professores. Esses preferem nem conhecer o diagnóstico dos estudantes, para não passar a vê-los como seres incapacitados, diante dessas questões, o docente 7 assim se manifestou:

\footnotetext{
Muitas vezes eu preferia não saber do diagnóstico, do laudo, porque ainda a gente está se acostumando com essa tal de inclusão, para nós, é uma situação nova, então, muitas vezes, saber que o aluno possui uma deficiência, causa até um prejuízo. Prejuízo no sentido de subestimar, ter dó, de limitar, dar pouco, rotular, aderir à ideia de que não adianta, fazer o que dá e pronto (Docente 7).
}

Essa visão vai ao encontro do pensar de Mittler (2003) sobre a educação inclusiva, de que a maior barreira a ser superada está dentro de cada pessoa, ou seja, a predisposição de subestimar o estudante com deficiência intelectual. É substancial refletir o pensamento da escola e dos educadores que nela atuam para construir a escola e a sociedade inclusiva.

O cenário representativo dos estudantes com deficiência intelectual no Ensino Médio demostrou que os docentes devem ter um olhar cauteloso sobre a realidade. Ainda não contamos com uma política de educação inclusiva na defesa desses estudantes em turmas regulares de ensino. São explícitas as legislações acerca das formações na educação de jovens com deficiência intelectual em turmas regulares do Ensino Médio, e é reduzida a discussão sobre as possibilidades educacionais para essas pessoas no campo acadêmico (CARVALHO, 2006). 
http://dx.doi.org/10.5902/1984686X55382

A educabilidade desses estudantes em turmas regulares do Ensino Médio pode representar uma variação positiva de acordo com a interpretação e condução que os professores mantiverem em relação ao atendimento educacional diferenciado. O papel do professor na escola inclusiva é fundamental, exige "ajudas, recursos e medidas pedagógicas especiais" (BLANCO, 2004, p. 291).

De acordo com o que se apresentou nas entrevistas pelos docentes, todos consideram as adaptações no currículo o caminho para diminuir as barreiras de aprendizagem que se apresentam aos estudantes com deficiência intelectual no ensino médio regular, afirmam que são condições necessárias para esses sujeitos terem o acesso aos níveis mais elevados de ensino, de se desenvolverem e de se constituírem como sujeitos, auxiliados sempre pelos educadores. Todos se posicionam favoráveis às adaptações curriculares, vislumbram que os estudantes podem desenvolver aprendizagens por meio da utilização de práticas pedagógicas condizentes às suas necessidades específicas, por meio de uma ação conjunta entre família, escola, poderes públicos e comunidade.

\section{O emprego das adaptações curriculares para estudantes com deficiência intelectual incluídos no ensino médio regular}

A Política de Educação Especial de Santa Catarina (2006), ao tratar das adaptações curriculares, fundamenta-se nos PCNs (BRASIL, 1998), que retratam a importância de as escolas flexibilizarem seus currículos para contemplar as diversidades que fazem parte dos contextos escolares.

Assim, entendemos que realizar adaptações curriculares na escola inclusiva é uma rica oportunidade de desenvolver o processo de ensino-aprendizagem por outros caminhos, que respeitem as condições e necessidades dos estudantes. Essa é a perspectiva que se apresenta para a escola inclusiva na rede estadual de ensino de Santa Catarina para os estudantes com deficiência intelectual, em que muitos desses não chegam a frequentar o Ensino Médio devido às dificuldades de serem compreendidos pelas suas limitações, e, consequentemente, acabam por não concluir a Educação Básica.

Com a preocupação de investigar a escola inclusiva frente ao atendimento desses estudantes, os docentes foram interrogados sobre a utilização das adaptações curriculares no Ensino Médio regular de acordo com o que consta na Política da Educação Especial de Santa Catarina (2006). Nesta categoria ficam expressas as materialidades geradas pela 
pesquisa sobre como os professores realizam as adaptações curriculares, a forma que constam no Projeto Político Pedagógico (PPP) das escolas e os benefícios que sua realização proporciona, nos dizendo.

Em relação às adaptações, nós não tínhamos uma quantidade tão grande de estudantes como temos hoje. A necessidade desse trabalho ser eficiente e ampliado é muito grande. Nós professores temos a noção, a ciência, de que o PPP é um documento que norteia nosso trabalho, que nós vamos nos ancorar todo tempo em todas as dificuldades, então nós estamos revendo ele todos os anos para incluir inclusive outras deficiências, as metodologias, os trabalhos realizados, as necessidades. Esse é o papel da escola, inclusive o nosso de professor, conseguir garantir esse espaço no PPP, o espaço sempre atualizado, porque a nossa demanda ela cresce a cada dia e com necessidades variadas, diferenciadas, então sempre tem uma preocupação com o PPP (Docente 6).

Os docentes observam que os estudantes da Educação Especial estão aumentando significativamente e que o PPP é o documento que contempla os rumos pensados pela escola. É o documento que contém as intenções de trabalho e de educação e que deve ser constantemente revisto para contemplar as mudanças e se adequar à realidade e às mudanças das legislações afins.

Segundo Figueiredo (2002), a ideia de adaptações curriculares de pequeno porte compreende modificações da alçada do professor nas ações planejadas para a aula, possibilitando a participação dos estudantes. Assim elas se constituem em expectativas para combater as dificuldades que os estudantes com deficiência apresentam. Frente a essa demanda, é necessário que o coletivo da escola defina o que vai fazer e como vão acontecer as ações educativas adaptadas com esses estudantes no contexto da escola inclusiva. É preciso registrar mais detalhadamente as metodologias empregadas no atendimento para os estudantes com deficiência intelectual, assim como também ocorre o atendimento em específico para esses estudantes, considerando suas diferenças em relação à classe.

Quanto à intervenção pedagógica com os estudantes que possuem deficiência intelectual no Ensino Médio regular, constatamos que os professores fazem adaptações em suas práticas, mesmo não constando detalhadamente nos projetos pedagógicos. De acordo com as experiências e o comprometimento com a docência, procuram adaptar as atividades com o objetivo de desenvolver o aprendizado e promover a inclusão.

Entendemos que a organização da escola inclusiva perpassa pela estruturação do seu PPP, e esse deve traduzir o percurso a ser feito para atingir as metas propostas e os desejos da escola que se almeja para todos. Persiste a necessidade de aprofundar debates, 
http://dx.doi.org/10.5902/1984686X55382

buscando aprimorar a forma como as adaptações curriculares devem atuar ou atuam no contexto da escola, definindo ações pedagógicas e estabelecendo os registros.

Quanto aos tipos de materiais que os professores adaptavam e como fazem seu processo adaptativo no Ensino Médio regular, eles responderam que são pensados no momento que realizam o planejamento das aulas para as turmas. Os docentes planejam o que pode ser feito com os estudantes, de acordo com o conteúdo a ser estudado, com apoio e orientação dos segundos professores sobre como podem trabalhar determinados conceitos, em consonância com cada temática. De acordo com o Docente 6,

\begin{abstract}
O primeiro passo é acertar o material para produção das adaptações e conhecer os alunos e a turma. Procuro diagnosticar os saberes, as potencialidades, habilidades e também as deficiências. Tento explorar muito isso, por exemplo, em qualquer tipo de conteúdo trabalhado e previsto para disciplina. Quando faço o planejamento para aquela turma específica do aluno, eu começo analisar o seu perfil. Associo ao conteúdo, à sua rotina, ao que ele gosta pelo que me mostrou, vejo suas potencialidades ou as suas facilidades e diminuo do conteúdo. Exploro de uma forma diferente, tento vários métodos, na maioria das vezes, usando mais a questão de conceitos com o uso de materiais práticos para que o conteúdo chegue de alguma forma para o aluno de maneira significativa. Trabalho de maneira que o aluno consiga relacionar aquilo com a vida dele, com a sociedade e a partir das coisas que conhece. É porque eu acho que ele estando envolvido, está inserido na sociedade e a história de vida nesses casos conta muito para explorar alguma coisa nesse sentido da adaptação.
\end{abstract}

Segundo a LDBEN n. 9.394 (BRASIL, 1996), as adaptações curriculares do contexto da sala de aula, chamadas de pequeno porte, são de competência mais específica do professor, mas é importante salientar que o estudante é de responsabilidade da escola. Sendo assim, a inclusão escolar exige que os professores estejam preparados para atuar em sala de aula com pessoas com deficiência intelectual, principalmente no Ensino Médio, em que os conteúdos são mais complexos e os processos de adaptação no currículo não são questões muito simplificadas, dependendo da disciplina.

Os docentes entrevistados manifestam suas considerações acerca do uso das adaptações dos materiais, afirmando ser fundamental conhecer sobre como as pessoas aprendem. Apontam como necessidade conhecer mais as teorias de Vigotsky, Piaget e da Proposta Curricular de Santa Catarina (1998) cujo aporte teórico é vigotskyano, embora haja outras versões mais recentes publicadas. Reafirmam a importância de conhecer o estudante, suas habilidades, potencialidades, não deixando de considerar os conceitos dos conteúdos básicos de cada componente curricular. As adaptações curriculares são produzidas a partir de recortes, figuras, relacionadas com trabalhos manuais, atividades lúdicas e práticas. É importante relacionar os conteúdos estudados com o cotidiano dos 
estudantes, situações mais práticas, contextualizadas com suas vidas. Ao analisar os depoimentos dos docentes, de como os professores compreendem e fazem uso das adaptações curriculares para os estudantes incluídos com deficiência intelectual no Ensino Médio, registramos que todos declararam realizar as adaptações no currículo, proporcionando mudanças nos modos de trabalhar e desenvolver os conhecimentos no contexto da escola inclusiva. Dentre eles, $80 \%$ trabalham com a construção dos conceitos da disciplina, com o uso de materiais pedagógicos, realizando as produções com atividades mais práticas.

Diante desta questão, constatamos que as práticas de adaptações curriculares na $4^{\mathrm{a}}$ CRE de Chapecó acontecem por meio do esforço/lutas pessoais e de grupos pelos docentes nas escolas. Ao realizarem o processo de adaptação, os docentes procuram verificar a importância dos conteúdos, significando-os, fazendo ajustes no tempo, na intensidade e na complexidade das atividades; planejam procurando trabalhar com atividades mais práticas e visuais; ofertam metodologias atrativas e condizentes às condições dos estudantes, realizam as mediações objetivando ampliar a construção de conceitos.

As adaptações curriculares são realizadas no Ensino Médio, mesmo diante de questões que precisam ser mais elaboradas e cumpridas, recomendadas pelos colaboradores do estudo: a) $O$ planejamento coletivo ocorre com baixa frequência; b) A construção de atividades conjuntas do professor da disciplina com os segundos professores de turma se sobressaem com bons resultados na classe, porém os professores não disponibilizam de tempo para elaboração das mesmas durante o período trabalhado; c) Necessidade de mais formação docente e continuada para os professores; d) Falta formação sobre a Proposta Curricular, BNCC e propostas pedagógicas específicas; e) Constantes mudanças e substituições do segundo professor na rede, dificultando a articulação do trabalho de docência; f) A maioria dos segundos professores não tem formação pedagógica para o atendimento a estudantes com deficiência intelectual.

Mesmo diante das circunstâncias presentes nas escolas da regional de Chapecó, a pesquisa aponta que os estudantes são beneficiados por adaptações curriculares realizadas pelos professores. Estes entendem que a escola, seja ela inclusiva ou não, tem a função de possibilitar, construir, reelaborar o conhecimento historicamente elaborado, propiciando condições para o desenvolvimento e conclusão da Educação Básica com aporte para a Educação Superior. 
http://dx.doi.org/10.5902/1984686X55382

Vigotsky (1997) incumbe à escola empreender todos os esforços possíveis para que os estudantes com deficiência intelectual consigam ir além do domínio dos conhecimentos cotidianos, contando com as transformações das funções psicológicas superiores. É neste contingente que as adaptações curriculares de pequeno porte realizadas em sala de aula pelo professor são o caminho para alcançar os conhecimentos elaborados historicamente.

Os estudantes com deficiência intelectual se apropriam das adaptações curriculares de pequeno porte, proporcionadas pelos professores em seus planejamentos de ensino, através das metodologias diferenciadas que os conduzem a se apropriarem dos conceitos trabalhados pelos componentes curriculares. Na escola inclusiva, o olhar deve ser diferenciado, o professor deve propiciar alternativas de acesso ao currículo, beneficiando o estudante, levando-o a ampliar seu pensamento, criatividade e promovendo o desenvolvimento das funções psicológicas superiores.

Os benefícios das adaptações curriculares estão no fato do professor viabilizar aos estudantes o sentimento de estarem no mesmo nível dos colegas de classe, estudando os mesmos conteúdos da turma, não os infantilizando no trabalho educativo. Assim, as adaptações feitas no currículo pelo professor permitem que o estudante com deficiência intelectual permaneça frequentando a escola como um direito, com autonomia, respeito às diferenças e viabilidades de acesso ao conhecimento sistematizado.

As práticas de adaptações curriculares de pequeno porte, efetivadas pelos professores na escola inclusiva, têm o objetivo de atender as diferenças, respeitando as individualidades, gerando equidade e cidadania.

\section{Desafios docentes acerca da realização das adaptações curriculares}

O fazer pedagógico com o uso de adaptações curriculares se faz presente nas escolas pesquisadas. As adaptações curriculares são o caminho para incluir e permitir que os estudantes com deficiência intelectual desenvolvam habilidades ou competências relacionadas à aquisição e produção de conhecimentos, desestabilizando as práticas corriqueiras e desarticuladas.

O maior desafio para realizar as adaptações curriculares para os estudantes com deficiência intelectual está na falta de formação continuada dos docentes. Muitos professores se sentem frágeis, pouco formados ou capacitados para realizar as adaptações no currículo. Compreendem que os estudantes precisam de atividades adaptadas como condição de se manterem frequentando e se apropriando dos conhecimentos ofertados via 
http://dx.doi.org/10.5902/1984686X55382

escola. Percebem também que, ao realizarem as adaptações em suas práticas, os estudantes manifestam suas compreensões e se interessam pela escola, aumentando a autoestima, ficam empolgados, no sentido de almejarem o acesso ao Ensino Superior.

As formações continuadas da temática sobre adaptação curricular para os estudantes com deficiência intelectual, promovidas pela Fundação Catarinense de Educação Especial (FCEE) e pela Secretaria Estadual de Educação (SED) na rede estadual aos professores dos componentes curriculares do Ensino Médio não estão acontecendo.

Em relação à formação acadêmica para atuar na Educação Especial, poucos professores têm essa formação, somente os mais jovens no magistério receberam maior formação nas licenciaturas, devido às mudanças na legislação ocasionada pela inclusão escolar, os professores com maior tempo de serviço não contam com essa condição. É preciso rever essa questão, as universidades deixam a desejar nesse sentido, os componentes curriculares do ensino superior merecem maior atenção.

Podemos assegurar que a formação dos docentes é um dos critérios importantes para garantir a presença dos estudantes com deficiência intelectual no Ensino Médio regular. O professor, estando qualificado para atuar frente à Educação Especial, busca planejar suas aulas, reconhecendo que as pessoas com deficiência intelectual também podem ser escolarizadas. Ele realiza a docência permitindo a escolaridade para uma fração de pessoas ignoradas historicamente dos bancos escolares.

O segundo desafio enfrentado pelos docentes está no tempo dedicado ao planejamento e na elaboração das adaptações curriculares para os estudantes com deficiência intelectual. Analisando os relatos dos docentes que atuam com os estudantes do Ensino Médio com deficiência intelectual, não possuem tempo exclusivo em suas cargas horárias de trabalho para se dedicarem ao planejamento da Educação Especial, permitindo que façam escolhas/organizações de metodologias diferenciadas, estudos, leituras e aplicação de atividades adaptadas para os estudantes de maneira individualizada. Deste modo, a condução das atividades de classe é prejudicada, e o professor não consegue ter tempo suficiente para preparar suas intervenções/mediações com os estudantes.

Os docentes lamentam não haver momentos no calendário para coletivizar/socializar entre os professores que atuam diretamente com os estudantes da Educação Especial e a coordenação pedagógica. Há pouco espaço de diálogo entre o professor titular da disciplina e o segundo professor de turma para que possam planejar juntos, realizar as adaptações 
http://dx.doi.org/10.5902/1984686X55382

no currículo e pensar novos caminhos de aprendizagem, respeitando as condições específicas dos estudantes.

Quanto ao planejamento coletivo, apenas a escola que atende na modalidade de Ensino Médio Inovador (EMI) possui garantidas quatro horas semanais, as demais escolas não contam com momentos específicos de planejamento. Fica transparente que o planejamento precisa garantir espaço nas escolas, permitindo ao professor condições de planejar suas ações educativas diante do que se apresenta.

O terceiro desafio para que as adaptações sejam garantidas no currículo do Ensino Médio regular está na necessidade de organizar uma conjugação de esforços para efetivar a Política da Educação Especial, que tem como objetivo orientar, acompanhar e avaliar a educação dos estudantes com necessidades especiais (SANTA CATARINA, 2018, p. 35).

Segundo os docentes colaboradores desse estudo, as escolas necessitam de equipes pedagógicas aliadas ao atendimento da Educação Especial. Constatamos que 40\% dos professores dos componentes curriculares do Ensino Médio da rede estadual não se sentem suficientemente preparados para atuar na educação inclusiva como desejariam. A escola com estudantes da Educação Especial necessita de equipe de trabalho especial para o acompanhamento dos professores, do planejamento e da execução das práticas para esse público.

Outra significativa colaboração vem das famílias dos estudantes, já que precisam colaborar e ao mesmo tempo participar no desenvolvimento de seus filhos. Muitas respostas que determinam as necessidades especiais do estudante/filho surgem por meio do diálogo com os pais. A inclusão escolar requer uma estreita parceria que envolve a relação entre a família e a escola.

As escolas inclusivas precisam estar ancoradas em contribuições que fogem da alçada do professor/docente. As famílias e a escola devem manter-se conectadas, e essas possibilidades demandam que a rede estadual de Santa Catarina amplie seu quadro de pessoal para viabilizar condições de atendimento nos espaços que possuem estudantes com necessidades especiais - deficiência intelectual frequentando a rede.

Os desafios da escolarização dos estudantes com deficiência intelectual no Ensino Médio são diversos, dentre eles o quarto desafio apontado pelos docentes, o mais emergente está na estrutura das escolas. Há falta de pessoas/equipes pedagógicas e de materiais didáticos pedagógicos que favoreçam a realização das adaptações curriculares para os estudantes com deficiência intelectual. Os estudantes com deficiência intelectual, 
que estão no Ensino Médio regular, necessitam de materiais que colaborem/facilitem as suas compreensões e, ao mesmo tempo, sejam atrativos para que continuem frequentando a escola.

Os docentes denunciam que as escolas não dispõem de insumos (materiais, equipamentos tecnológicos) para o planejamento e administração das aulas. Nessas condições, as aulas se tornam pouco produtivas, interessantes e convidativas para que os estudantes com deficiência intelectual possam manter-se operantes aos conteúdos apresentados.

Para que os professores no Ensino Médio regular estabeleçam práticas educativas, refletidas na teoria histórico-cultural de Vigotsky (2011), promovendo atividades planejadas e adaptadas para os estudantes com deficiência intelectual, os ambientes escolares devem disponibilizar de estruturas com materiais e equipamentos que auxiliem nas interações sociais. Tais adaptações possibilitam respeitar questões biológicas, não reduzindo ou facilitando as atividades, mas aumentando o grau de complexidade conforme o processo de conhecimento for evoluindo. As adaptações são instrumentos facilitadores junto do professor para haver aprendizagem.

Dentre os vários problemas na escola inclusiva, contamos com o quinto desafio de escolarizar os jovens com deficiência intelectual no Ensino Médio. Isso exige várias mudanças do professor, como: transformação das metodologias, forma de acolhimento, respeito, inovação tecnológica social, cultural e conhecimento de causas.

O professor, como responsável pelo planejamento e organização das atividades, deve estabelecer afinidade com os estudantes. A escola que atende seus estudantes de maneira inclusiva deve promover o processo educativo contemplando, envolvendo e valorizando os avanços e conquistas diárias de seus estudantes. Desse modo, os estudantes sentem-se atraídos e, ao mesmo tempo, respeitados pelos professores que mostram diferentes caminhos para chegar a atingir o conhecimento.

A pesquisa evidenciou que dentre os professores da rede estadual de ensino de Santa Catarina, existem professores que se desafiam a planejar práticas educativas que incluem o estudante com deficiência intelectual nas atividades propostas para a classe. Tais professores elaboram planos de ensino adaptados e, quando necessário, individualizados, no sentido de contemplar o estudante com deficiência intelectual.

Apesar dos avanços, existem obstáculos a serem vencidos diante da realização das adaptações curriculares. O sexto desafio é ter uma escola estruturada, com a valorização 
http://dx.doi.org/10.5902/1984686X55382

dos profissionais da educação, principalmente aqueles responsáveis por ministrarem as aulas para os estudantes com necessidades especiais, ou seja, os professores dos diferentes componentes curriculares.

A acessibilidade ao currículo tem a ver com a valorização dada ao trabalho do professor, evidenciando que as diferenças fazem parte do dia a dia das pessoas, sendo obrigação da instituição incluir o estudante ao currículo. Ao estudante que é negado a possibilidade de participar das atividades escolares por falta de equipamentos ou materiais, se está excluindo do direito de escolarização.

Com estrutura escolar adequada, o professor tem maiores condições de ofertar adaptações no currículo, mas se a escola for sucateada não há estímulos para o trabalho. Concomitantemente além da falta da estrutura física e material, praticamente não ocorre a valorização humana. Logo, promover a inclusão escolar com adaptações curriculares gera apreensões na rede estadual de Santa Catarina. Os sujeitos entrevistados externam que não há como realizar adaptações curriculares com qualidade para os estudantes com deficiência intelectual no Ensino Médio regular sem garantir a viabilização das diretrizes da política da Educação Especial com uma estrutura que contemple professores formados e capacitados em número suficiente, recursos financeiros necessários para adquirir equipamentos, materiais pedagógicos e promoção da acessibilidade.

Neste contexto temos a dimensão da importância do trabalho dos professores, fazendo adaptações nas atividades diárias dos estudantes com deficiência intelectual. Os resultados são surpreendentes no desenvolvimento desses sujeitos na escola regular, mas um dos grandes desafios apresentados nessa pesquisa é fazer com que todos os educadores possam assumir essa prática, como uma política eficaz na Educação Especial de Santa Catarina.

A investigação evidenciou que os estudantes já contam com o benefício das adaptações curriculares. Os colaboradores dessa pesquisa anunciaram como se sentem os estudantes que já foram beneficiados por essa prática educativa, assim como a repercussão da ação na escola tem significado para esses estudantes. Portanto, a credibilidade das adaptações curriculares para os estudantes com deficiência intelectual é um grande desafio, o sétimo indicado na pesquisa, em que devem ser avalizadas por todos os professores da rede como um caminho a ser seguido. 
Dos docentes entrevistados, contamos com a maioria que acreditam nas adaptações curriculares e visualizam a diferença que a escola e a conquista do Ensino Médio fazem na vida desses jovens estudantes com deficiência intelectual.

A manifestação docente destaca que, quando a escola trabalha com a apropriação dos conhecimentos científicos, com uso de metodologias que promovem 0 desenvolvimento desses estudantes, eles avançam, podendo, dentro de suas condições, virem a frequentar cursos de nível superior.

Para esse grupo de docentes que representaram em 60\%, a credibilidade das adaptações curriculares já não são um desafio no Ensino Médio regular. Elas representam necessidades para que os números da Educação Básica em relação ao dado de frequência e de conclusão dos estudantes com deficiência intelectual apresente alterações positivas, assegurando melhores condições de vida pela contribuição da escola inclusiva.

O desafio é recorrente com aqueles docentes que ainda não entenderam que as práticas adaptativas ao currículo possibilitam respeitar as diversidades contidas nas escolas de ensino regular, cabendo à escola inclusiva esse importante papel diante dos estudantes com deficiência intelectual, principalmente os que chegam ao Ensino Médio. Tais conquistas permitem abrir uma porta emperrada socialmente, dando autonomia e esperança aos estudantes com deficiência intelectual poder viver dignamente através da conquista da Educação Básica.

\section{Considerações finais}

O Ensino Médio possui questões imperiosas para serem revistas na rede estadual de Santa Catarina. Há necessidade de melhorias das condições ofertadas para os professores para que possam viabilizar as adaptações curriculares aos estudantes com deficiência intelectual incluídos no Ensino Médio.

Os professores sabem o importante valor que possui a escola para esses estudantes, expressando com propriedade que a escola é o caminho para torná-los com condições de viverem dignamente. Contudo, esses mesmos professores precisam ser assistidos e valorizados para conseguirem fazer a função que cabe à escola, melhorando a vida das pessoas pela construção do conhecimento.

Dos professores pesquisados, $40 \%$ dizem não ter formação suficiente e compatível para exercer a docência com segurança frente aos estudantes com deficiência intelectual. Alegam não terem sido preparados (científica, cultural e socialmente) pelas instituições de 
http://dx.doi.org/10.5902/1984686X55382

Ensino Superior para atuar como profissionais da Educação Especial em escolas públicas e privadas.

Os calendários letivos chegam da SED para as escolas já definidos, ou seja, não permitem flexibilizações. As escolas não possuem autonomia suficiente para organizar espaços de debates coletivos, para pensar processos adaptativos, metodologias de atendimento, elaboração de planos individualizados, enfim, refletir formas de melhor entender e atender os estudantes no Ensino Médio com deficiência intelectual.

As escolas não contam com equipes pedagógicas/pessoas devidamente habilitadas e qualificadas em número suficiente para dar suporte aos professores no atendimento dos estudantes com deficiência intelectual. $\mathrm{Na}$ ausência desses profissionais, não há participação das famílias na escola e os professores sentem-se fragilizados diante da responsabilidade de suas docências. Perante o atual cenário, as adaptações curriculares em muitos momentos são negligenciadas aos estudantes com deficiência intelectual, resultando em perdas/prejuízos, devido à escola não atender considerando suas diferenças.

Esse número de questões/situações problemas acaba por ampliar os números da evasão, repetência, resistência dos estudantes com deficiência intelectual para frequentar o Ensino Médio regular nas escolas públicas da rede estadual de ensino de Chapecó.

A realização da inclusão escolar com práticas de adaptações curriculares ainda é um obstáculo a ser vencido. No Ensino Médio, as adversidades são ainda maiores, não existem legislações específicas para essa área de ensino. Muitos estudantes, por não receberem o atendimento escolar que considere suas limitações, reprovam, tendo como consequência o abandono da escola, e em muitos casos voltam a viver segregações sociais.

A Secretaria de Estado da Educação (SED) e a Fundação Catarinense da Educação Especial (FCEE), órgãos gestores e responsáveis pela Educação Especial nas escolas da rede estadual de ensino de Santa Catarina, necessitam estabelecer metas, criar programas, viabilizar recursos objetivando estruturar as escolas, dando condições aos profissionais para realizarem o atendimento dos estudantes da Educação Especial de acordo com o que cita na atual LDBEN.

Analisando as falas dos docentes colaboradores dessa pesquisa, percebemos que eles têm ciência da realidade que vive a atual escola pública, mostraram-se preocupados com a realização das adaptações curriculares nas escolas do Ensino Médio. Compreendem que elas são ferramentas pedagógicas significativas para trabalhar com os estudantes com 
deficiência intelectual, buscando incluí-los e respeitá-los nas suas diferenças. Conhecem e sabem da grandeza que representam para o desenvolvimento dos estudantes com necessidades especiais, sua utilização no processo ensino aprendizagem pressupõe atender à diversificação de necessidades dos estudantes das escolas (BRASIL, 1998).

Ficou expresso que o emprego com maior segurança pelos docentes das adaptações curriculares como uma prática pedagógica de atendimento aos estudantes com deficiência intelectual no Ensino Médio implica em maiores conhecimentos por: leituras, formação continuada, estudos científicos direcionados para os professores dos diferentes componentes curriculares. Ainda, disponibilidade de tempo para planejar coletivamente com assessorias pedagógicas nas escolas, materiais/equipamentos pedagógicos pertinentes de qualidade ao Ensino Médio.

De acordo com os docentes entrevistados, os professores têm se desafiado e muitas adaptações curriculares já acontecem nas escolas pesquisadas. Alguns docentes conseguem adaptar mais atividades, outros menos, porém, os professores proporcionam adaptações curriculares aos estudantes com deficiência intelectual. A relação com a quantidade e peculiaridade do material adaptado e ofertado para os estudantes tem relação com a experiência, com o compromisso, o conhecimento e a formação que os professores possuem.

As práticas pedagógicas de adaptações curriculares feitas pelos docentes na regional de Chapecó contemplam sinais de êxitos de um processo educativo complexo, mas com muitas marcas positivas, como essa expressa na fala emocionada de uma docente colaboradora desta pesquisa: "[...] as adaptações curriculares fazem muito a diferença com os estudantes com deficiência intelectual, eles passam a serem pessoas mais autônomas e felizes!"

\section{Referências}

AAIDD - American Association on Intellectual and Developmental Disabilities. Definição de deficiência intelectual. 2018. Disponível em: https://aaidd.org/home. Acesso em: 9 fev. 2020.

BARDIN, L. Análise de Conteúdo. Tradução Luis Antero Reto e Augusto Pinheiro. São Paulo: Edições 70, 2016. 
BLANCO, R. A atenção à diversidade na sala de aula e as adaptações do currículo. In: COLL, C.; PALÁCIOS, J.; MARCHESI, Á. (Org.). Desenvolvimento psicológico e educação: transtornos de desenvolvimento e necessidades educativas especiais. 2. ed. Porto Alegre: Artmed, 2004. v. 3. p. 290-308.

BRASIL. (Constituição 1988). Constituição da República Federativa do Brasil. Brasília, DF: Centro Gráfico, 1988.

BRASIL. Lei n. 9.394, de 20 de dezembro de 1996. Estabelece as Diretrizes e Bases da Educação Nacional. Diário Oficial da União, Brasília, DF, p. 27833, 20 dez. 1996.

BRASIL. Ministério da Educação. Secretaria de Educação Especial. Política Nacional da Educação Especial na Perspectiva da Educação Inclusiva. Brasília: Ministério da Educação, 2008.

BRASIL. Ministério da Educação. Secretaria de Educação Fundamental. Secretaria de Educação Especial. Parâmetros Curriculares Nacionais: adaptações curriculares. Brasília: Ministério da Educação, 1998.

BUDEL, G.; MEIER, M. Mediação da Aprendizagem na Educação Especial. Curitiba: IBPEX, 2012.

CARVALHO, M. F. Educação de jovens e adultos com deficiência mental: inclusão escolar e constituição dos sujeitos. Horizontes, São Paulo, v. 24, n. 2, p. 161-171, jul./dez. 2006. Disponível em: https://revistahorizontes.usf.edu.br/horizontes/issue/archive. Acesso em: 11 dez. 2019.

FIGUEIREDO, R. V. Políticas de Inclusão: escola-gestão da aprendizagem na diversidade. In: ROSA, D. E. G.; SOUZA, V. C. (Org.). Políticas organizativas e curriculares, educação inclusiva e formação de professores. Rio de Janeiro: DP\&A, 2002. p. 67-78.

GADOTTI, M. História das ideias pedagógicas. 8. ed. São Paulo: Ática, 2003. LARROSA, J. Elogios da escola. Tradução Fernando Coelho. Belo Horizonte: Autêntica, 2017.

INEP - Instituto Nacional de Estudos e Pesquisas Educacionais Anísio Teixeira. Resumo Técnico: Censo da Educação Básica 2018. Brasília: INEP, 2019.

MARCHESI, Á. A prática das escolas inclusivas. In: COLL, C.; PALÁCIOS, J.; MARCHESI, Á. (Org.). Desenvolvimento psicológico e educação: transtornos de desenvolvimento e necessidades educativas especiais. 2. ed. Porto Alegre: Artmed, 2004. p. 31-48.

MINETTO, M. F. O currículo na educação inclusiva: entendendo esse desafio. 2. ed. Curitiba: IBPEX, 2008.

MITTLER, P. Educação Inclusiva: contextos sociais. Porto Alegre: Artmed, 2003. 
PADILHA, A. M. L. Práticas pedagógicas na educação especial: a capacidade de significar o mundo e a inserção cultural do deficiente mental. São Paulo: Autores Associados, 2001.

PAULON, S. M.; FREITAS, L. B. L.; PINHO, G. S. Documento subsidiário à política de inclusão. Brasília: Ministério da Educação; Secretaria de Educação Especial, 2005.

PIRES, E. C. S.; SANCHES, A. A.; TORRES, W. R. Dificuldades dos portadores de necessidades especiais na inclusão educacional. Unitins, 2011. Disponível em: http://ava2.unitins.br/ava/files/projetoconteudo/cccfd876821308039570f71ae697d083.html . Acesso em: 10 out. 2017.

SANTA CATARINA. Secretaria de Estado da Educação. Fundação Catarinense de Educação Especial. Política de Educação Especial do Estado de Santa Catarina. Coordenador Sergio Otavio Bassetti. São José, SC: FCEE, 2006.

SANTA CATARINA. Secretaria de Estado da Educação. Política de Educação Especial. Florianópolis: Secretaria de Estado da Educação, 2018.

SANTA CATARINA. Secretaria de Estado da Educação e do Desporto. Proposta Curricular de Santa Catarina: Educação Infantil, Ensino Fundamental e Médio: Temas Multidisciplinares. Florianópolis: COGEN, 1998.

VIGOTSKI, L. S. A defectologia e o estudo do desenvolvimento e da educação da criança anormal. Educação e Pesquisa, São Paulo, v. 37, n. 4, p. 863-869, dez. 2011. Disponível em: https://www.scielo.br/pdf/ep/v37n4/a12v37n4.pdf. Acesso em: 10 out. 2019.

VIGOTSKI, L.S. A formação social da mente. São Paulo: Martins Fontes, 2010.

VIGOTSKI, L.S. Obras Escogidas - V: Fundamentos da Defectologia. Tradução Julio Guillermo Blank. Madrid, Espanha: Machado Nuevo Aprendizaje, 1997.

\section{Notas}

${ }^{1}$ A grafia do nome do autor varia em diferentes traduções. Optamos por uma só forma, "Vigotsky", porém preservamos as indicações diferenciadas nas Referências, conforme cita Luria no livro Formação social da mente (VIGOTSKI, 2010, p. 16).

${ }^{2}$ Segundo a American Association on Intellectual and Developmental Disabilities (AAIDD, 2018) a deficiência intelectual é o estado de redução notável do funcionamento intelectual, da capacidade do indivíduo em responder adequadamente às demandas da sociedade em comunicação, cuidados pessoais, competências domésticas, habilidades sociais, utilização dos recursos comunitários, autonomia, saúde e segurança, aptidões escolares, lazer e trabalho.

${ }^{3}$ No ano de 2020, o termo deficiência mental foi substituído por deficiência intelectual, sendo essa definida como "[...] uma limitação de funcionamento mental, como prejuízo de comunicação, cuidados pessoais e relacionamento social" (BUDEL; MEIER, 2012, p. 76).

${ }^{4} \mathrm{~A}$ investigação realizada atingiu o PPP das escolas através de questionamentos aos docentes no momento das entrevistas. 


\section{Correspondência}

Vania Salete Cassol Daga - Rua Castelo Branco no 517, Centro, Águas Frias, Santa Catarina, Brasil.

CEP: 89843-000

\section{(c) (i) (8)}

This work is licensed under a Creative Commons Attribution-NonCommercial 4.0 International (CC BY-NC 4.0) 